$14^{\text {th }}$ International Conference on

AEROSPACE SCIENCES \& AVIATION TECHNOLOGY,

ASAT - 14 - May 24 - 26, 2011, Email: asat@mtc.edu.eg

Military Technical College, Kobry Elkobbah, Cairo, Egypt

Tel: +(202) 24025292-24036138, Fax: +(202) 22621908

\title{
Preliminary Sizing of an Agricultural Aircraft
}

\author{
I. A. Yousif * and M. Elhadi A. E. ${ }^{\dagger}$
}

\begin{abstract}
This paper aims to preliminary size an agricultural aircraft that meets the agricultural requirements in Sudan and could be manufactured locally and be equipped with an engine that works with cheaper type of fuel (Jet-A1). The specifications have been obtained from existing similar aircraft designs working in Sudan then the standard design procedure has been reproduced. The aerodynamic parameters have been obtained using FLUENT. The primary results were found qualitatively acceptable but need extensive verification. Finally a UAV down-scaled model has been constructed and a flight test has been carried out and the aircraft taxed, took off and landed safely. That indicated a good aircraft configuration.
\end{abstract}

Keywords: Agricultural aircrafts, aerodynamics, wing, fuselage, tail unit design.

$\begin{array}{ll}\text { Nomenclature } \\ \mathrm{I}_{\mathrm{h}} & \text { Incidence angle } \\ \Lambda & \text { Sweep angle } \\ \lambda & \text { Taper ratio } \\ \Gamma & \text { Dihedral angle } \\ \mathrm{L}_{\mathrm{f}} & \text { Fuselage length } \\ \mathrm{d}_{\mathrm{f}} & \text { Fuselage diameter } \\ \theta_{\mathrm{fc}} & \text { Fuselage cone angle }\end{array}$

\section{Abbreviations}

$\begin{array}{ll}\text { AERO-RC } & \text { All engine operative-Rate of climb } \\ \text { H.T } & \text { Horizontal tail } \\ \text { M.A.C } & \text { Mean aerodynamic chord } \\ \text { V.T } & \text { Vertical tail }\end{array}$

\section{Introduction}

Agricultural aviation usually refers to agricultural, forestry, fishing and public health types. It is in fact an aerial application; i.e. the distribution of chemicals and seeds from the air on the surface of the land or water, or on vegetation plants. One should nevertheless remember that agricultural aviation also includes such work as aerial survey for agricultural purpose such as land use, livestock inventories, detection of crop diseases, locust detection and fire patrols.

The need of new design comes from high direct operation cost that arises from high costly fuel consumption and expensive spare parts.

\footnotetext{
* M.Sc. Student, Karary University, B.Sc. Sudan University, smileyousif@gmail.com

${ }^{\dagger}$ Assistant Prof., Karary University, Aeronautical Dept., mohadi20@hotmail.com
} 


\section{Preliminary Sizing}

\subsection{Specifications}

\section{Name of project}

Payload (liquid chemical)

Crew weight (one pilot)

Range

Endurance

Initial rate of climb

Service ceiling

Absolute ceiling

Field length

Field width

Power plant
SEAD-8

2204lb

$220.41 \mathrm{~b}$

460 Mile

3 hours

$1170 \mathrm{ft} / \mathrm{s}$

$10,000 \mathrm{ft}$

$25,000 \mathrm{ft}$

$3280.8-3937 \mathrm{ft}$

$32.8-49.2 \mathrm{ft}$

One Turboprop engine using Jet-A1 fuel type

A/C must meet FAR-23 requirements for stall, cruise speed, T.O landing distance, climb rate.

\subsection{Aircraft Weight Estimation}

The takeoff weight is given by [1];

$$
\begin{gathered}
W_{T . O}=W_{O . E}+W_{F}+W_{P L} \\
W_{O . E}=W_{E}+W_{T F O}+W_{C R E W}
\end{gathered}
$$

The fuel weight $\mathrm{W}_{\mathrm{F}}$ (as fraction of $\mathrm{W}_{\text {T.O }}$ ) can be obtained from mission profile of aircraft that is shown in Fig. 1 following standard procedures as detailed in [1].

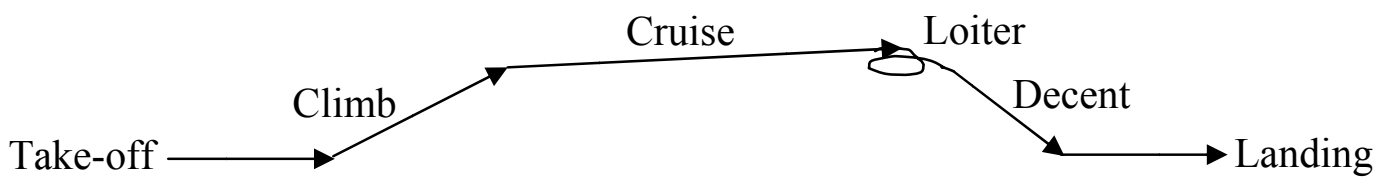

Fig. 1 Mission profile for SEAD-8

\subsection{Estimating Aircraft Design Parameters}

The estimated aircraft weight has been obtained from the intersection between algebraic and logarithmic lines as in Fig. 2, while constants A and B were obtained from [1]. Different values of wing loading (w/s), power loading (w/p) and maximum lift $\mathrm{C}_{\mathrm{Lmax}}$ have been calculated according to FAR23. Then the design parameters (wing area, take-off power, maximum lift coefficient for clean, take-off and landing configuration and wing aspect ratio) have been obtained by selecting the appropriate point (intersection between two blue lines) as illustrated in Fig. 3 based on the highest wing loading and lowest power loading.

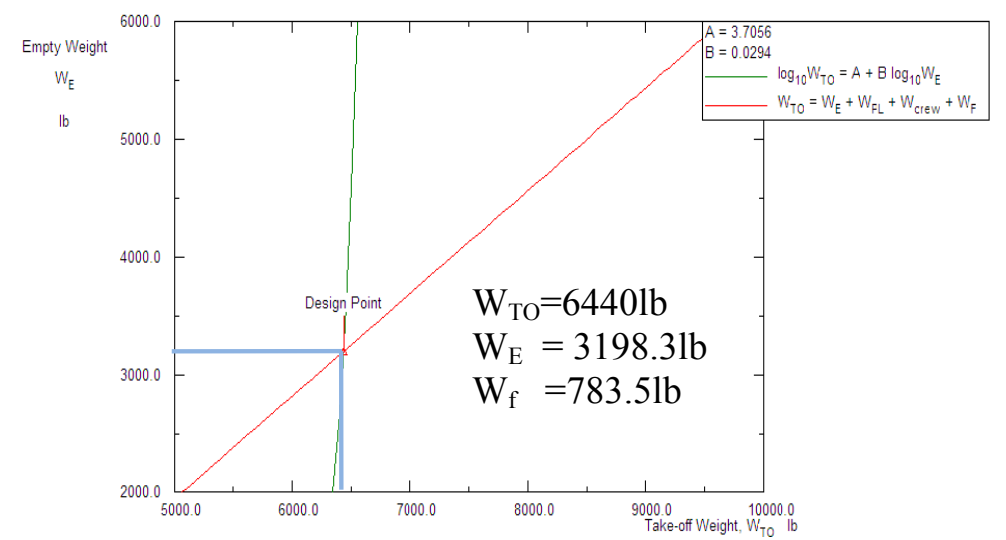

Fig. 2 Weight trend for SEAD-8 


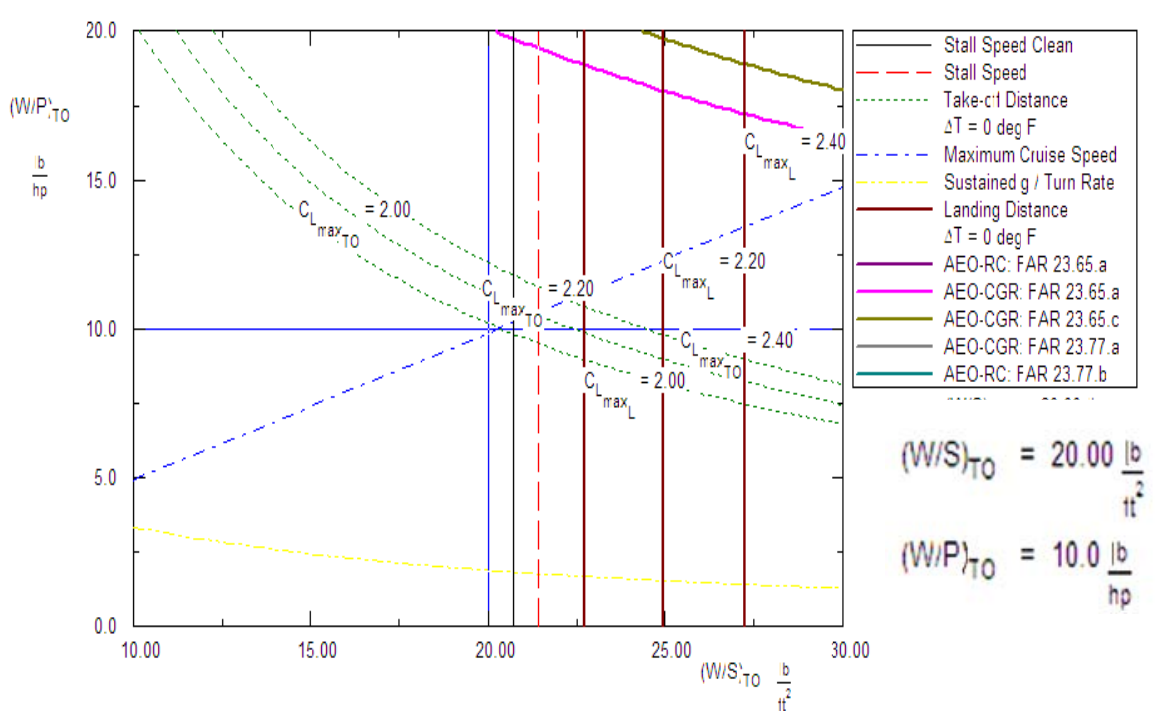

Fig. 3 Design point according to maximum W/S and minimum W/P

The wing area and power required can be determined as follows;

$$
\begin{gathered}
S=\frac{W_{T O}}{(W / S)}=6440 / 20=322 \mathrm{ft}^{2} \\
P=\frac{W_{T O}}{(W / P)}=6440 / 10=644 \mathrm{hp}
\end{gathered}
$$

$\mathrm{C}_{\mathrm{Lmax}}$ values are from Fig. 3.

$\begin{array}{ll}\text { Clean } & =1.7 \\ \text { Take-off } & =2.0 \\ \text { Landing } & =2.2\end{array}$

And the appropriate value of aspect ratio $\mathrm{AR}=6$.

Table (1) compares SEAD-8 with medium weight category agricultural aircraft.

Table 1 Comparison between SEAD-8 and other Ag-aircrafts

\begin{tabular}{l|c|c|c|c|c|c|c|c}
\hline \hline \multirow{2}{*}{ Type } & $\begin{array}{c}\text { Max T.O. } \\
\text { Weight }\end{array}$ & $\begin{array}{c}\text { Empty } \\
\text { Weight }\end{array}$ & $\begin{array}{c}\text { Wing } \\
\text { loading }\end{array}$ & $\begin{array}{c}\text { Wing } \\
\text { area }\end{array}$ & $\begin{array}{c}\text { Power } \\
\text { loading }\end{array}$ & $\begin{array}{c}\text { Max Cont. } \\
\text { Power }\end{array}$ & $\begin{array}{c}\text { Hooper } \\
\text { load }\end{array}$ & $\mathrm{V}_{\mathrm{S}}$ \\
\cline { 2 - 10 } & $\mathrm{Lb}$ & $\mathrm{lb}$ & $\mathrm{lb} / \mathrm{ft}^{2}$ & $\mathrm{Ft}^{2}$ & $\mathrm{lb} / \mathrm{hp}$ & $\mathrm{Hp}$ & $\mathrm{lb}$ & $\mathrm{kts}$ \\
\hline \hline Ag-Cat 'Fat Cat' & 4500 & 2455 & 13.72 & 328 & 5.99 & 657 & 2000 & 68 \\
\hline Zlin Z-137T & 5566 & 2900 & 14.20 & 392 & 9.28 & 600 & 1984 & - \\
\hline Ayres S2R & 6000 & 3600 & 18.40 & 326 & 8.00 & 700 & 4638 & 77 \\
\hline Sead-8 & $\underline{\mathbf{6 4 4 0}}$ & $\underline{\mathbf{3 1 9 8 . 3}}$ & $\underline{\mathbf{2 0 . 0}}$ & $\underline{\mathbf{3 2 2}}$ & $\underline{\mathbf{1 0 . 0}}$ & $\underline{\mathbf{6 4 4}}$ & $\underline{\mathbf{2 2 0 4 . 6}}$ & $\underline{\mathbf{6 0}}$ \\
\hline 750XL AG & $\mathbf{7 5 0 0}$ & 3825 & 28.01 & 267.8 & 10.00 & 633 & 4410 & 69 \\
\hline \hline
\end{tabular}

\subsection{Arrangement of the Major Aircraft Components}

The preliminary arrangement of major components involving 'fuselage configuration', 'engine type, number of engines and engine disposition', 'wing type and disposition', 'empennage type and disposition', 'landing gear type and disposition' is discussed in the following sections. 


\subsubsection{Fuselage layout design}

\section{Design of cockpit and fuselage layout}

Fuselage is carrying one pilot and his equipment and chemical tank (hopper) systems. The fuselage geometric parameters shown in Fig. 4 for agricultural aircraft were chosen as displayed in Fig. 5 from statistical study but both the ratio of length of fuselage cone to maximum diameter and angle of cone $\frac{l_{f c}}{d_{f}}, \theta_{f c}$ are out of range due to nose L.G. configuration.

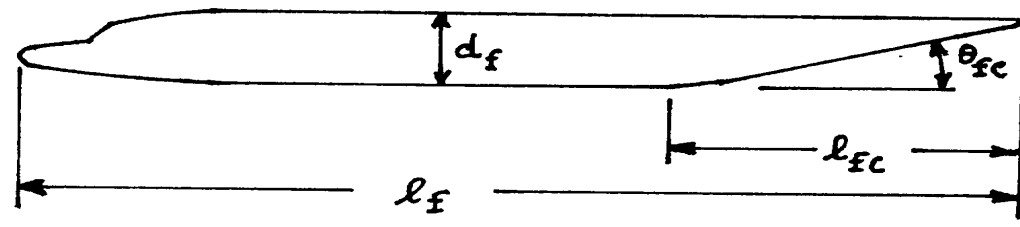

$$
\frac{L_{f}}{d_{f}}=5-8, \quad \frac{L_{f c}}{d_{f}}=3-4, \quad \theta_{f c}=1^{o}-7^{o}
$$

Fig. 4 Geometric parameters of the fuselage, [2]

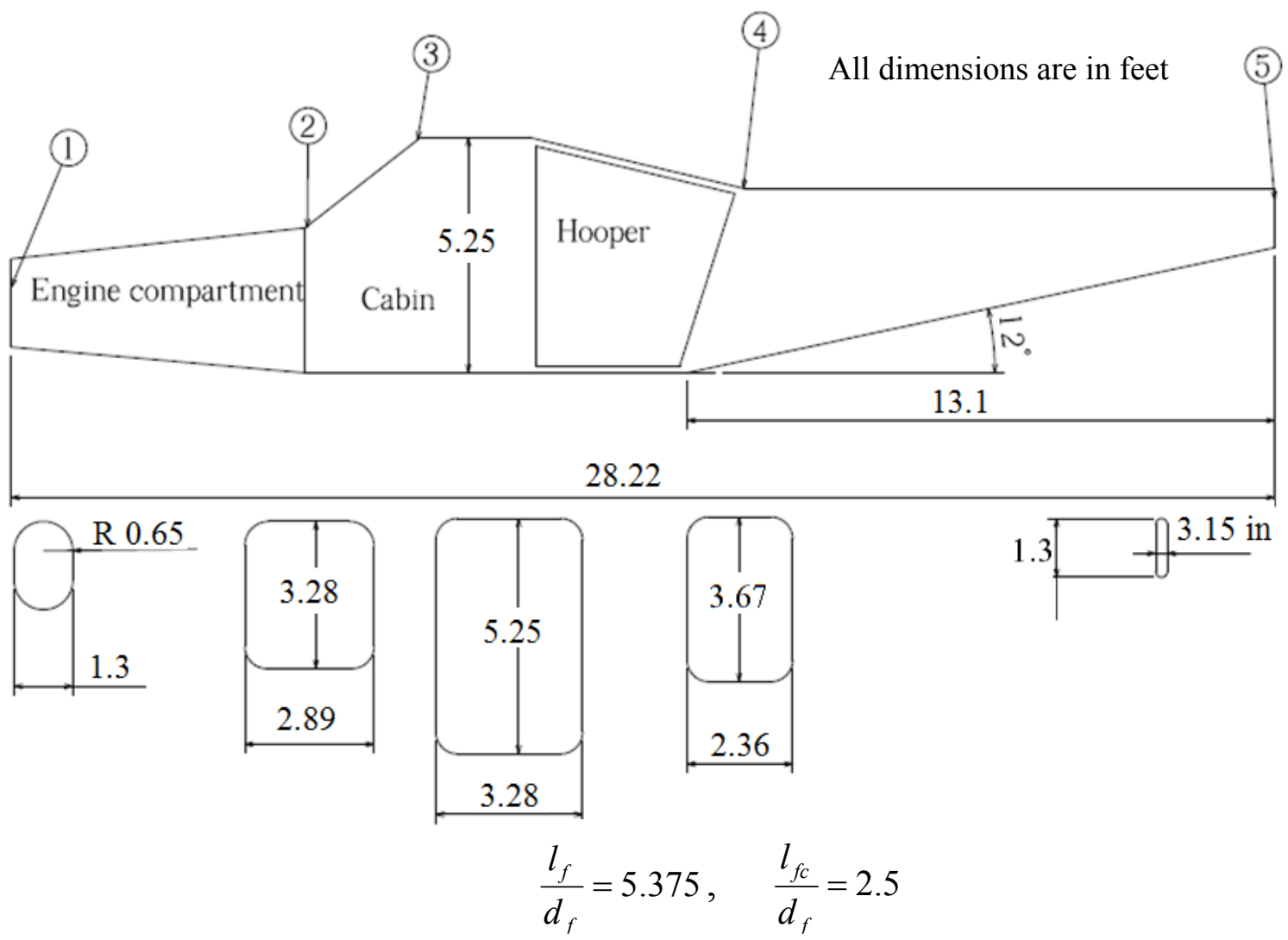

Fig. 5 SEAD-8 fuselage layout and section design

\subsubsection{Selection of propulsion system type}

A tractor installed propeller type with two blades has been selected. The blade-power-loading $\left(\mathrm{P}_{\mathrm{bL}}\right.$ 5.0), the propeller diameter is calculated from:

$$
D_{P}=\left\{4 P \max /\left(\pi n_{P} P_{b l}\right)\right\}^{0.5}=9.2 f t=2.8 m
$$


Accordingly a Pratt \& Whitney PT6A-34AG engine (Fig. 6), has been selected which has the specifications listed in Table 2.

Table 2 Engine Specification

\begin{tabular}{c|l}
\hline \hline Model & PT6A-34AG \\
\hline Power SHP & 750 SHP \\
\hline Power BHP & 670 BHP \\
\hline Diameter & $19 "$ \\
\hline Length & $62 "$ \\
\hline RPM & 2200 \\
\hline \hline
\end{tabular}
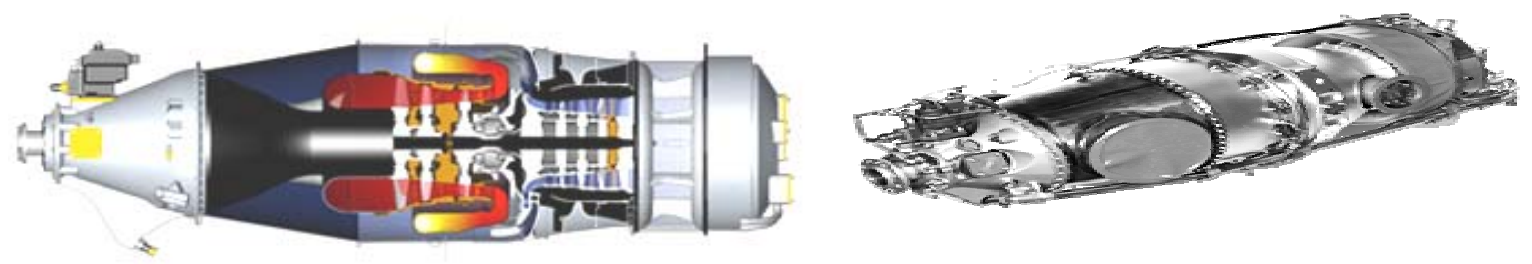

Fig. 6 SEAD-8 engine layout

\subsubsection{Wing planform design and sizing and locating lateral control surfaces}

The wing is characterized by wing area $(S)$, Aspect ratio $(A)$, Sweep angle $\left(\Lambda_{C / 4}\right)$, Thickness ratio $(t / c)$, Airfoils, Taper ratio $\left(\lambda_{W}\right)$, Incidence angle $\left(i_{w}\right)$, Twist angle $\left(\varepsilon_{i}\right)$, Dihedral angle $\left(\Gamma_{W}\right)$ and Lateral control surface size and layout.

\subsubsection{Wing sizing}

The wing has been chosen as a low cantilever type. The wing span has been calculated from aspect ratio as $44 \mathrm{ft}$ with mean Chord $7.3 \mathrm{ft}$.

The geometric characteristics have been selected from a comprehensive statistical study for similar types as;

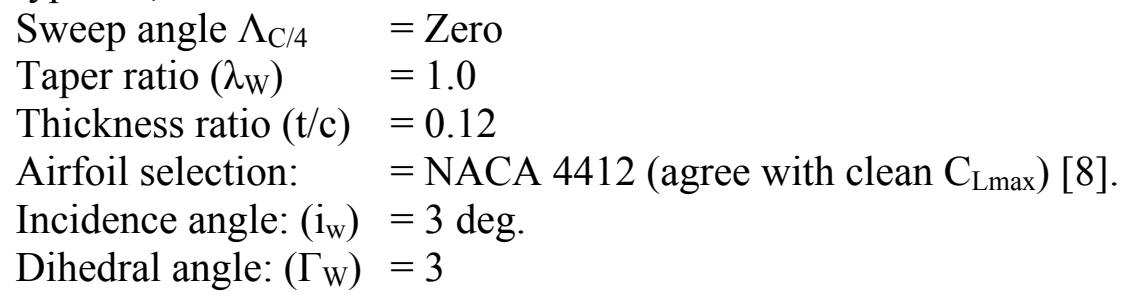

\subsubsection{Sizing high lift devices}

Computing the required value of increment section lift coefficient $\left(\Delta \mathrm{C}_{\mathrm{L}}\right)$, which the flaps must generate and relating this value to flap type, flap angle and flap chord, as in Fig. 7.
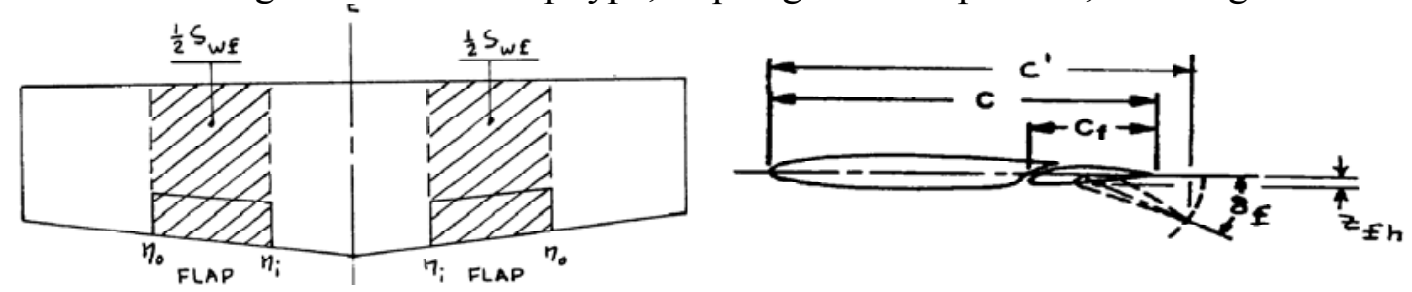

Fig. 7 Flapped wing area and flap stations and parameters [2]

$$
\Delta C_{l \max }=\left(\Delta C_{L \max }\right)\left(S / S_{w f}\right)\left(K_{\Lambda}\right)
$$

where $\Delta \mathrm{C}_{\mathrm{L}}(0.3)$ at T.O. and (0.5) at landing and $\mathrm{K}_{\Lambda}$ is $(0.92)$. 


$$
\begin{gathered}
\Delta C_{L}=C_{L_{\alpha}} \alpha_{\delta_{F}} \delta_{F} \\
C_{L_{\alpha F}}=C_{L_{\alpha}}(\bar{C} / C) \\
(\bar{C} / C)=1+2\left(Z_{f h} / C\right) \tan (\delta / 2)
\end{gathered}
$$

From statistical study as detailed in ref. [2]:

Distance ratio

$$
\mathrm{Z}_{\mathrm{fh}} / \mathrm{c}=0.1
$$

Flap chord to m.a.c ratio

$$
\mathrm{C}_{\mathrm{f}} / \mathrm{C}=0.25
$$

Flapped wing area

$\mathrm{S}_{\mathrm{wf}} / \mathrm{S}=0.33$

Flap deflection in T.O.

$\delta_{\text {fTO }}=10 \mathrm{deg}$.

Flap deflection in landing

$\delta_{\mathrm{fL}}=15 \mathrm{deg}$.

$$
S_{w f} / S=\left(\eta_{0}-\eta_{i}\right)\left[2-(1-\lambda)\left(\eta_{0}-\eta_{i}\right)\right] /(1+\lambda)
$$

Flap stations as in (Fig. 7) $\quad \eta_{\mathrm{i}}=0.12, \quad \eta_{\mathrm{o}}=0.45$

Figure 8 describes wing plan form with flap with supposed location of front and rear spars in dashed lines while the fuselage station in dotted line.

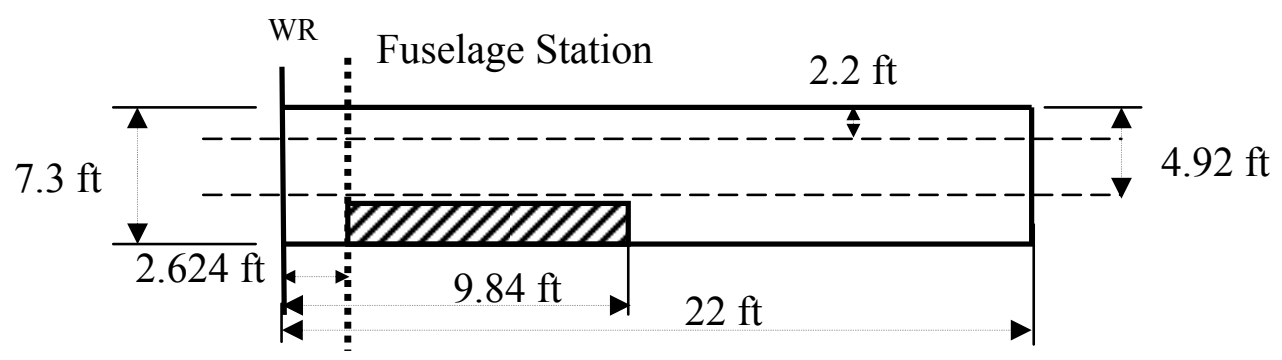

Fig. 8 Wing dimensions

\subsubsection{Empennage design}

The empennage has been sized as a conventional configuration, the canard configuration has not been adopted, and the tail unit position is in rear of fuselage [2].

\subsubsection{Horizontal tail sizing}

The required parameters to size H.T is wing area, wing m.a.c. H.T volume $\mathrm{V}_{\mathrm{h}}=0.4$ and distance from C.G to H.T m.a.c. $\mathrm{X}_{\mathrm{h}}=14 \mathrm{ft}$ and H.T. aspect ratio $\mathrm{A}_{\mathrm{h}}=3$ and elevator area to H.T area $\mathrm{S}_{\mathrm{e}} / \mathrm{S}_{\mathrm{h}}=0.25$ selected from statistical study as follows;

$$
\begin{gathered}
S_{h}=\frac{V_{h} S C}{X_{h}}=67.2 f t \\
A_{h}=b^{2} / S_{h}
\end{gathered}
$$

Airfoil selection: $\quad=$ NACA 0009

H.T span, $\mathrm{b}_{\mathrm{h}} \quad=14.2 \mathrm{ft}$

H.T chord, $\mathrm{C}_{\mathrm{h}} \quad=4.7 \mathrm{ft}$,

Elevator area, $\mathrm{S}_{\mathrm{e}} \quad=16.8 \mathrm{ft}^{2}$,

Elevator chord, $\mathrm{C}_{\mathrm{e}} \quad=1.5 \mathrm{ft}$,

Elevator span, $b_{\mathrm{e}}=14 \mathrm{ft}$,

$\mathrm{I}_{\mathrm{h}}=0, \quad \Lambda_{\mathrm{c} / 4}=0, \quad \lambda_{\mathrm{h}}=1$, 


\subsubsection{Vertical tail sizing}

As previous, the required parameters to size H.T is wing area, wing span, V.T volume $\mathrm{V}_{\mathrm{v}}=0.022$ and distance from C.G to V.T m.a.c. $\mathrm{X}_{\mathrm{v}}=13 \mathrm{ft}$ and V.T. aspect ratio $\mathrm{A}_{\mathrm{v}}=1.3$ and elevator area to V.T. area $\mathrm{S}_{\mathrm{r}} / \mathrm{S}_{\mathrm{v}}=0.3$ selected from statistical study [2].

$$
\begin{gathered}
S_{v}=\frac{V_{v} S b}{X_{v}} \\
\mathrm{~A}_{\mathrm{v}}=\mathrm{b}^{2} / \mathrm{S}_{\mathrm{v}}
\end{gathered}
$$

Airfoil selection: NACA 0012

$$
\begin{array}{ll}
\text { V.T area, } \mathrm{S}_{\mathrm{V}} & =23.98 \mathrm{ft}^{2} \\
\text { V.T span, } \mathrm{b} & =5.6 \mathrm{ft} \\
\text { Rudder area, } \mathrm{Sr} & =7.2 \mathrm{ft}^{2} \\
\text { Rudder chord, } \mathrm{C}_{\mathrm{R}} & =1.3 \mathrm{ft} \\
\text { V.T tapper ratio, } \lambda_{\mathrm{V}} & =0.74 \\
\text { V.T sweep angle, } \Lambda_{\mathrm{c} / 4}= & 15 \mathrm{deg} . \\
& C_{\text {root }}=2 S / b(1+\lambda)
\end{array}
$$

Rudder root chord, $\mathrm{C}_{\text {root }}=5 \mathrm{ft}$

Rudder tip chord, $\mathrm{C}_{\text {tip }}=3.7 \mathrm{ft}$

$$
C_{\text {Mean }}=\frac{2}{3} C_{\text {root }}\left(1+\lambda+\lambda^{2}\right) \quad Y=\frac{b}{6}(1+2 \lambda) /(1+\lambda)
$$

V.T mean chord, $\mathrm{C}_{\text {Mean }}=4.38 \mathrm{ft}$

\subsubsection{Landing gear disposition}

Two geometric criteria that need to be considered in deciding the disposition of the landing gear strut are:

\section{i- Tip-over criteria}

The main landing gear must be behind the aft C.G location, the $\left(15^{\circ}\right)$ angle which usually represents the relation between main gear and aft C.G. as clear from Fig. 9.

\section{ii- Ground clearance criteria}

The lateral ground clearance angle and the longitudinal ground clearance angle apply to tricycles. Accordingly, the following values have been determined;

Longitudinal ground clearance criterion:- $B a s e=11.8 \mathrm{ft}$, distance enough to prevent nose-over and to prevent tail from touching the ground Fig. 9.

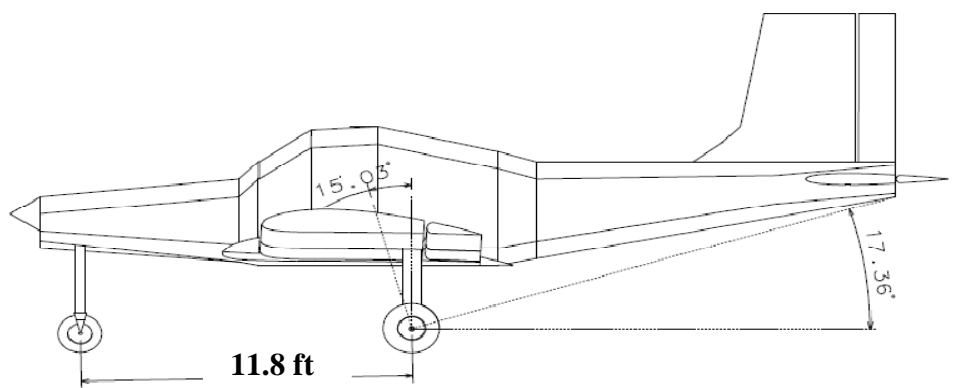

Fig. 9 Landing gear lateral tip over criteria

Lateral ground clearance criterion

Angle $54^{\circ}$ is quite enough to avoid tip-over (protect wing tips from touching ground when aircraft is turning). Track $=11.8 \mathrm{ft}$ (distance between wheels) is enough to create the angle as in Fig. 10. 


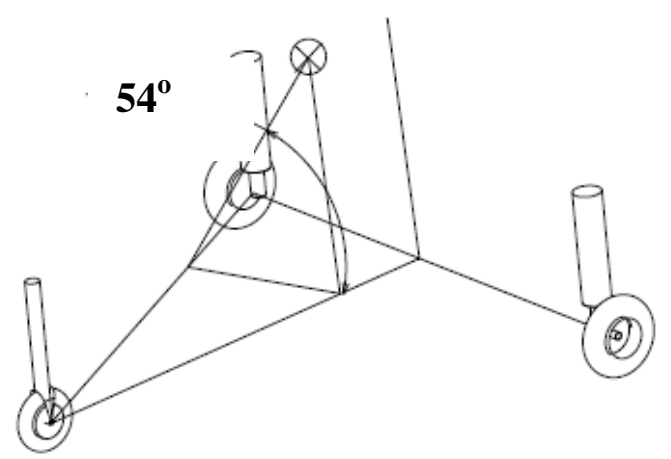

Fig. 10 Landing gear longitudinal tip over

\subsection{Aircraft Weight and Balance}

The initial component weight breakdown is shown in Table 3 using weight prediction methods [5]. The center of gravity location has been determined as shown in Table 3 below.

Table 3 SEAD-8 C.G. location (forward or afterward)

\begin{tabular}{l|l|l|l|r|r}
\hline \hline \multicolumn{1}{c|}{ Component } & $\begin{array}{c}\text { Weight } \\
\mathrm{lb}\end{array}$ & \multicolumn{1}{c|}{$\begin{array}{c}\mathrm{X} \\
\text { in }\end{array}$} & \multicolumn{1}{c|}{$\begin{array}{c}\mathrm{Y} \\
\text { in }\end{array}$} & \multicolumn{1}{c}{$\begin{array}{c}\mathrm{W}_{\mathrm{i}} \mathrm{X}_{\mathrm{i}} \\
\mathrm{lb.in}\end{array}$} & \multicolumn{1}{c}{$\begin{array}{c}\mathrm{W}_{\mathrm{I}} \mathrm{Y}_{\mathrm{i}} \\
\mathrm{lb} \text { in }\end{array}$} \\
\hline \hline Horizontal tail & 83.51 & 327.3 & 3.2 & 27332.82 & 267.232 \\
\hline Vertical tail & 35.79 & 301.7 & 78.0 & 10797.84 & 2791.62 \\
\hline Fuselage & 355 & 118.4 & 66 & 42032 & 23430 \\
\hline Wing & 891.1 & 111.8 & 3.2 & 99624.98 & 2851.52 \\
\hline Main gear & 173.52 & 149.6 & -26.0 & 25958.59 & -4511.52 \\
\hline Nose gear & 43.38 & 12.6 & -39.4 & 546.588 & -1709.17 \\
\hline Fixed equips & 712.4 & 94.5 & 102.4 & 67321.8 & 72949.76 \\
\hline Engine & 851.6 & 50.4 & 20.5 & 42920.64 & 17457.8 \\
\hline Foreword C.G. & $\underline{\mathbf{3 1 9 8 . 3}}$ & $\underline{\mathbf{1 0 0 . 1}}$ & $\underline{\mathbf{3 6 . 3}}$ & & \\
\hline Pilot & 220.4 & 118.1 & 31.5 & 26029.2 & 6942.6 \\
\hline Fuel & 783.5 & 126.0 & 3.2 & 98721 & 2507.2 \\
\hline Chemical load & 2204.6 & 163.8 & 26.8 & 326280.8 & 57319.6 \\
\hline Aft word C.G & $\underline{\mathbf{6 4 0 6 . 8}}$ & $\underline{\mathbf{1 2 0}}$ & $\underline{\mathbf{2 8 . 8}}$ & & \\
\hline \hline
\end{tabular}

\subsection{Aircraft Overall Configuration}

Autodesk ${ }^{\circledR}$ AutoCAD has been used to draw the aircraft external layout as illustrated in Fig. 11.

\section{CFD Predictions}

Due to symmetry, only half model is used as displayed in Fig. 12 and demonstrates the surface mesh of half model while Fig. 13 shows the mesh of the entire domain.

Table 4 lists the resulted lift, drag and moment coefficients for three different values of angle of attack. 

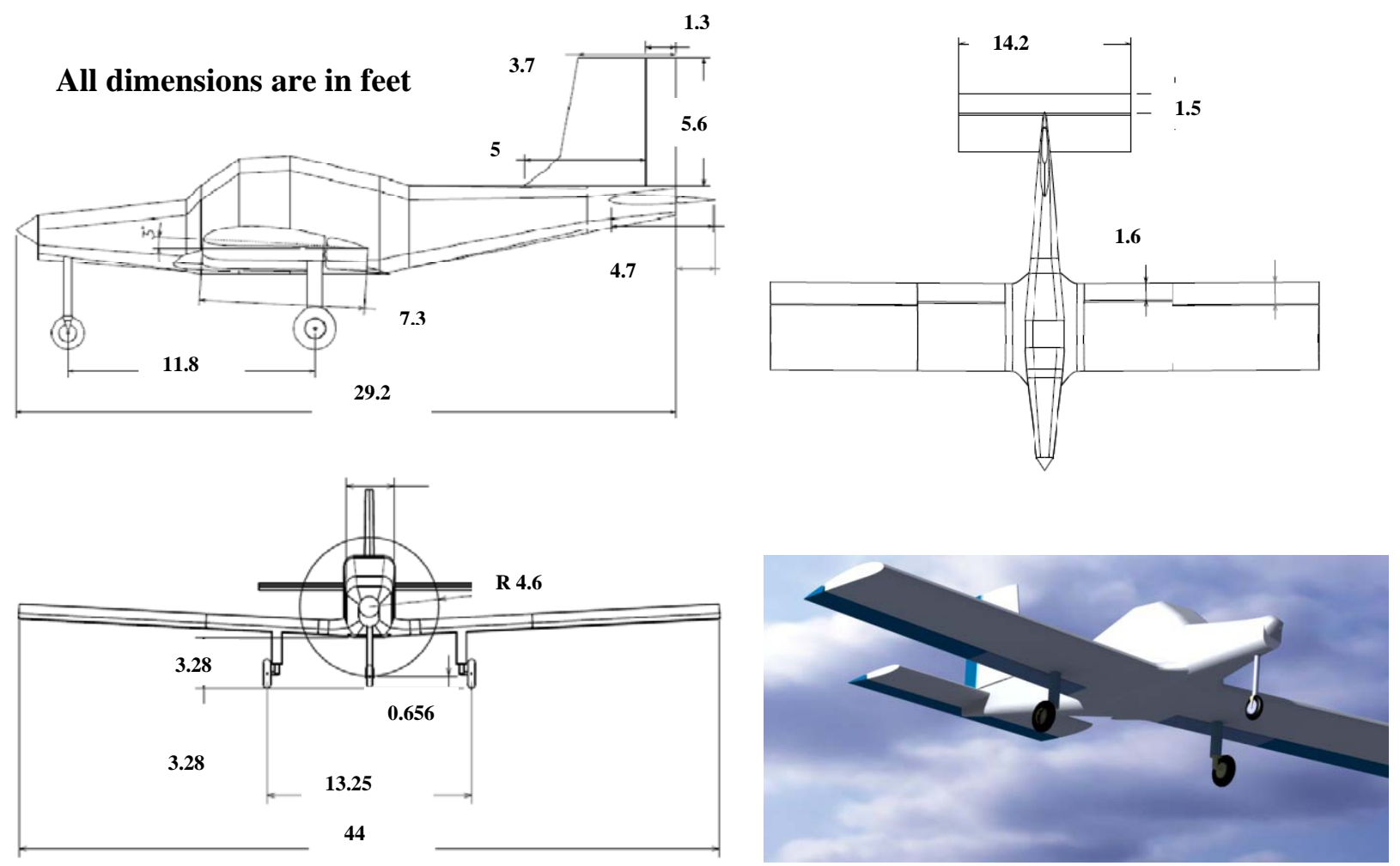

Fig. 11 SEAD-8 3-D view

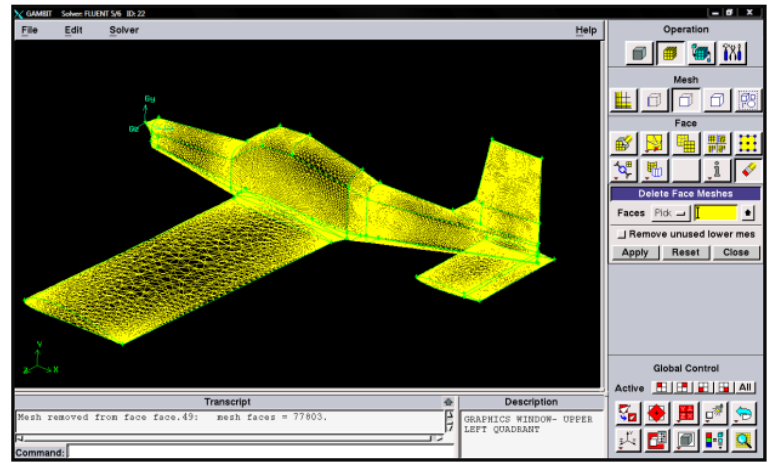

Fig. 12 SEAD-8 meshed surface

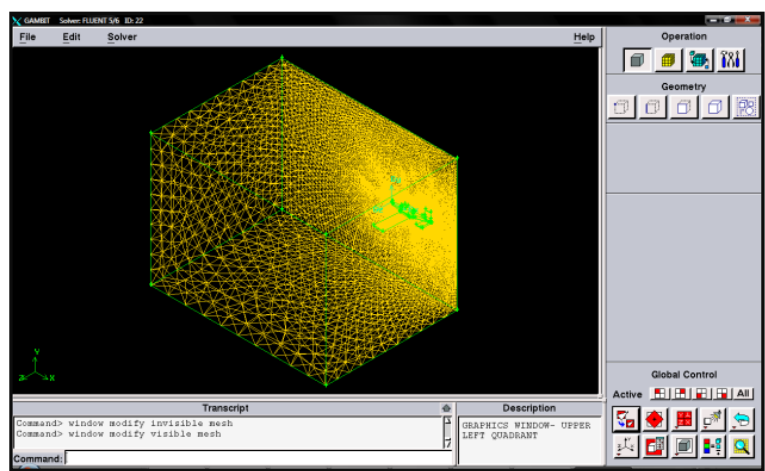

Fig. 13 Meshed domain
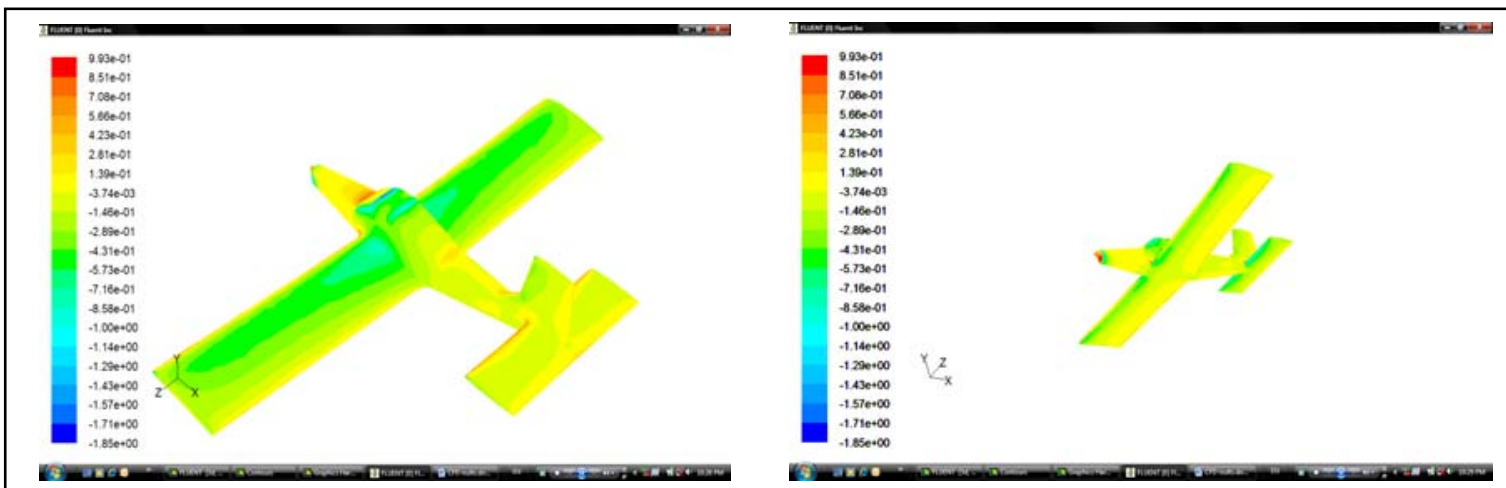

Fig. 14 Pressure distribution on upper and lower surfaces. 
Table.4 Aerodynamic derivatives obtained form CFD

\begin{tabular}{c|c|c|c}
\hline \hline Angle of attack, $[\mathrm{deg}]$ & $\mathrm{C}_{\mathrm{L}}$ & $\mathrm{C}_{\mathrm{D}}$ & $\mathrm{C}_{\mathrm{M}}$ \\
\hline \hline-4 & 0.0911467 & 0.02471999 & 0.0010672 \\
\hline 0 & 0.0089899 & 0.25545 & 0.023397 \\
\hline 4 & 0.25544468 & 0.0233903 & 0.01571 \\
\hline \hline
\end{tabular}

\section{Aircraft Testing as a UAV}

Due to practical reasons the actual aircraft size was difficult to be manufactured and tested. A scaled down aircraft model has been manufactured as a UAV to prove that the aircraft is flyable. The scale factor 1:6.5 $(\mathrm{N}=15 \%)$ has been used to fabricate the model [9]. To ensure the dynamic similarity of the flow, there are two criteria, namely geometrical similarity and flow similarity parameters; i.e. Reynolds number and Mach number. For low speed Reynolds number similarity is more significant.

$$
\operatorname{Re}=\frac{\rho V d}{\mu}=\frac{\rho V_{m}(0.15 d)}{\mu}
$$

Because the test was made in the atmosphere $\rho$ and $\mu$ are the same for the full scale and downscaled model, the difference will appear mainly in the velocity e.g. $\mathrm{V}_{\mathrm{s} \text { model }}=0.15 \mathrm{~V}_{\mathrm{s}}$ actual . The aircraft weight and wing area were found from;

$$
\begin{aligned}
L_{m} & =L_{A} N \\
S_{m} & =S_{A} N^{2} \\
W_{\mathrm{m}}=21.735 \mathrm{lb} & =W_{A} N^{3},
\end{aligned}
$$

Figure 15 shows shabloons which were made and used to fabricate wing and fuselage.

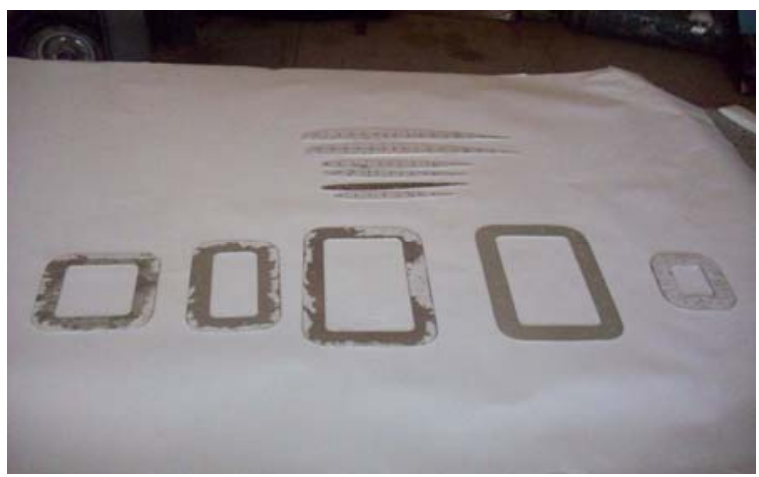

Fig. 15 SEAD-8 shabloons

Assembled UAV is ready to test for flying as shown in Fig.16 and was successfully taxed, took-off as demonstrated in Fig. 17 and smoothly maneuvered as displayed in Fig. 18 and then safely landed as clear in Fig. 19. That confirmed that the external configuration was quite acceptable.

\section{Conclusion and Recommendations}

According to the assumed customer specifications, the paper has undertaken the tasks of weight estimation, fuselage layout design, wing sizing, high lift device sizing, empennage design, landing gear disposition, weight and balance, CFD predictions, UAV manufacturing. Stability issue has to be addressed in a more extensive approach. Namely DATCOM is suggested for determining stability derivatives. These issues are subject to comprehensive analysis being conducted presently by the authors and will be published later. 


\section{References}

[1] Roskam J., airplane design: part I, preliminary sizing of airplane.

[2] Roskam J., airplane design: part II, preliminary configuration design and integration of propulsion system

[3] Roskam J., airplane design: part III, layout design of cockpit, fuselage wing and empennage: cutaways and inboard profiles, Roskam j., airplane design: part IV, layout design of landing gear and system.

[4] Roskam J., airplane design: part V, component weight estimation.

[5] Roskam J., airplane design: part VI, preliminary calculation of aerodynamic, thrust and power characteristics.

[6] Roskam J., airplane design: part VII, determination of stability, control and performance. roskam aviation and engineering corporation, 1985

[7] Denial P. Raymer, Aircraft Design: A Conceptual Approach, AIAA Washington, DC, Second Edition, Second Printing, 1992.

[8] Abbott, I.H. and Von Doenhoff, A.E, theory of wing sections, Dover publications, N.Y., 1959.

[9] Ishak, Iskandar Shah and Mat, Shabudin and Mat Lazim, Tholudin and Muhammad, Mohd. Khir and Mansor, Shuhaimi and Awang, Mohd Zailani (2006) Experimental and simulation Studies of a Two Seater Light Aircraft. In: 1st Regional Conference on Vehicle Engineering \& Technology, 3-5 July 2006, Kuala Lumpur, Malaysia http://www.eprints.utm.my/303/

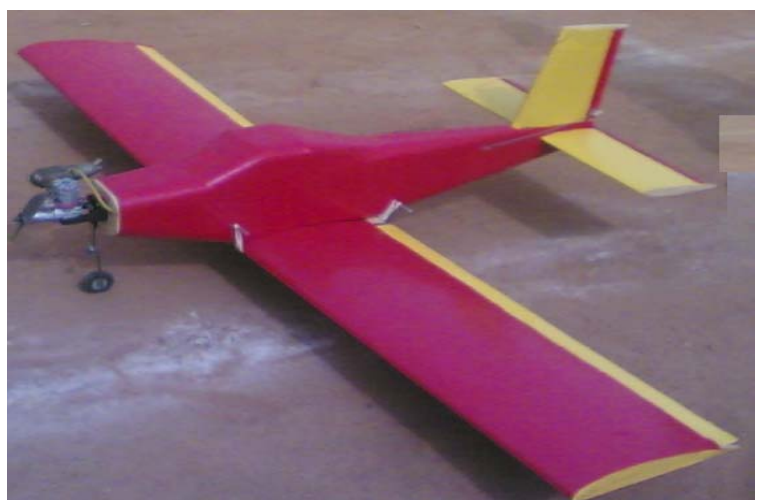

Fig. 16 SEAD-8 as UAV

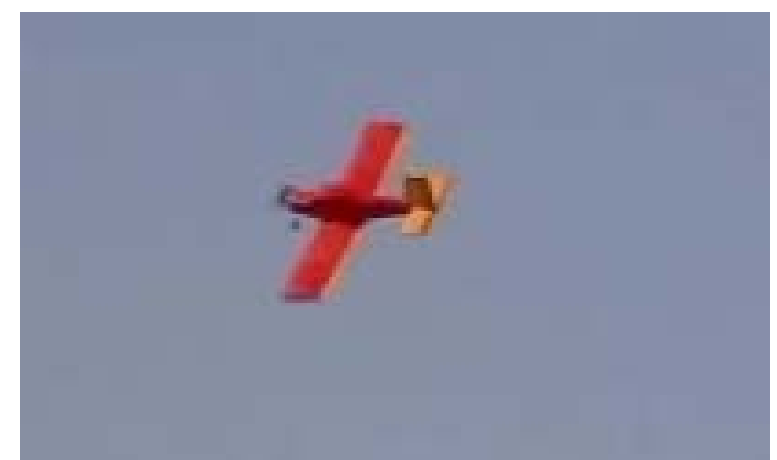

Fig. 18 UAV at maneuvering

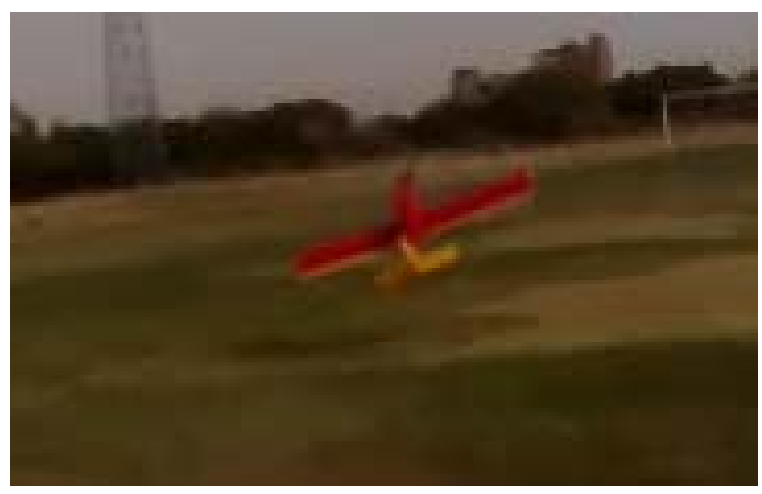

Fig.17 UAV at take-off

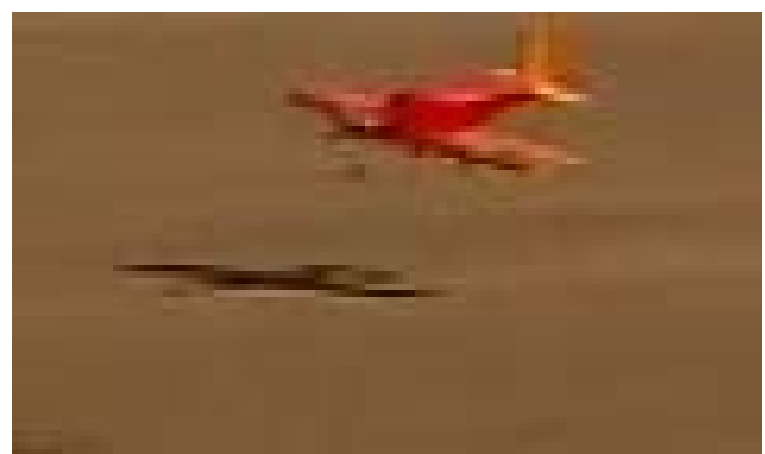

Fig. 19 UAV at landing 